\title{
DA PEDRA BRUTA À JOIA RARA, A LEITURA QUE LAPIDA, DESCOBRE, BRILHA E VALORA
}

\author{
From rough stone to rare jewelry, reading that straws, \\ discovers, shines and value
}

Izandra ALVES

Instituto Federal do Rio Grande do Sul - Campus Feliz izandra.alves@feliz.ifrs.edu.br http://orcid.org/0000-0002-6063-3753

Janaína VIEIRA

Instituto Federal do Rio Grande do Sul - Campus Feliz vieirajana@hotmail.com http://orcid.org/0000-0002-8780-3943

\begin{abstract}
RESUMO: Este estudo busca refletir sobre a ação do mediador da leitura, que tem em suas mãos o poder de auxiliar para a formação de um leitor entendedor ou de um simples decodificador. Dessa forma, trazemos presente a discussão sobre a importância do processo de instigar os educandos à leitura possibilitando-os ver que através dela é possível compreender melhor a si mesmo e a sociedade em que se está inserido e, a partir disso, encontrar perspectivas de acesso a novos caminhos. Este trabalho se apóia em uma pesquisa-ação junto a alunos de oitavo ano de uma escola pública do interior do Rio Grande do Sul. Em encontros mediados pela leitura, os estudantes são instigados a escrever sobre si mesmos a partir dos textos que leem. Assim, apoiados em teóricos da área da leitura como Vicent Jouve, Alberto Manguel e Michèle Petit, traçamos paralelos entre as teorias dos autores e as vivências desses jovens leitores em busca da (re)construção de si.
\end{abstract}

PALAVRA-CHAVE: Mediador; Leitura; Pesquisa-ação; Ressignificação.

\begin{abstract}
This study seeks to reflect on the action of the reading mediator, who has the power to assist in the formation of an understanding reader or a simple decoder. In this way, we bring the discussion about the importance of the process of instigating students to reading, enabling them to see that through it, it is possible to better understand themselves and the society in which they are inserted and, from that, find perspectives of access to new paths. This work is supported by an action research with eighth grade students from a public school in the interior of Rio Grande do Sul. In meetings mediated by reading, students are encouraged to write about themselves from the
\end{abstract}


texts they read. Thus, based on reading theorists such as Vicent Jouve, Alberto Manguel and Michèle Petit, we draw parallels between the theories of the authors and the experiences of these young readers in search of the (re) construction of themselves.

KEYWORDS: Mediator; Reading; Action Research; Resignification.

\section{INTRODUÇÃO}

Ao observar a diferença que há entre o ato de ler e o ato de entender, os quais inúmeras vezes não são trabalhados em sala de aula como situações distintas, fica evidente à contribuição da escola na formação de decodificadores e não de leitores. Desta forma, por compreender que o mediador de leitura tem em suas mãos o poder de auxiliar para a formação de um leitor entendedor ou de um simples decodificador é que este trabalho se justifica.

Pensando nisso, este trabalho discorre sobre a importância do processo de instigar os educandos à leitura mostrando que, através dela, é possível compreender melhor a si mesmo, consequentemente, a sociedade em que se está inserido e, a partir disso, encontrar possibilidades de acesso a novos caminhos. Conforme menciona a estudiosa francesa Michèle Petit (2009, p. 61), "a leitura é um meio para se ter acesso ao saber, aos conhecimentos formais e, sendo assim, pode modificar as linhas de nosso destino escolar, profissional e social".

Este artigo traz o recorte de um trabalho de pesquisa-ação realizado em uma escola estadual de Ensino Fundamental, na cidade de Feliz/RS, com uma turma do oitavo ano, composta por onze alunos, com a qual realizamos o estágio de docência do curso de Licenciatura em Letras do Instituto Federal de Educação, Ciência e Tecnologia do Rio Grande do Sul - Campus Feliz. Desta forma, nos propomos analisar em que medida o mediador da leitura pode contribuir para a formação do leitor, assim como perceber que efeitos o contato com a leitura pode ocasionar no leitor. Encontros entre leitor, mediador e texto foram promovidos com o intuito de despertar o protagonismo dos adolescentes em suas ações/reações a partir dos textos. Como o espaço deste artigo não permite explorarmos todas as ações realizadas com o grupo, destacaremos alguns momentos do trabalho que contribuíram para os resultados que tivemos.

Somos sabedores de que a dificuldade que os alunos apresentam para compreender 
determinados textos faz com que se sintam desestimulados e, devido a isso, por não compreenderem o que leem, se sentem incapazes para outros tantos "fazeres". Como consequência disso, como percebemos em seus próprios relatos, suas expectativas com relação ao futuro diminuem, visto que a maioria relata não ter perspectivas para dar continuidade à educação básica e que frequentam as aulas apenas por obrigação.

Levando em conta essa realidade, apresentamos a esses estudantes a leitura como um sinônimo de oportunidade, o que implica no estímulo ao autoconhecimento, a ler e a entender o mundo para, a partir deste entendimento, agir de forma autônoma na sociedade. Isso porque compreendemos que, por meio da leitura, mesmo que esporádica, podem estar mais preparados para resistir aos processos de marginalização, pois ela pode ajudar a se reconstruírem, a imaginar outras possibilidades, a sonhar, a encontrar um sentido, a mobilizarem-se no tabuleiro social. A suspensão proporcionada pela leitura, fornece, então, a distância necessária que dá sentido ao humor, bem como a pensar nesses tempos em que o pensamento se faz raro (PETIT, 2009).

Por acreditar em tudo isso é que ações mediadoras de leitura são necessárias e urgentes. Por isso, este trabalho de investigação propôs-se a criar ações que auxiliem na mediação de leitura a fim de melhorar a relação dos estudantes com o ato de ler e, formar leitores apaixonados.

Para sustentar nossas discussões, nos apoiamos nos estudos de Michèle Petit (2009), que nos apresenta um conceito de leitura capaz de abrir portas em direção à interioridade, à afetividade inexplorada e ao campo da sensibilidade e, para que essas portas se abram, é importante que os leitores sejam recepcionados por uma leitura que os interesse. Buscamos aclarar o sentido da palavra leitura e analisamos como o ato de ler pode ser favorável para a aquisição de autoconhecimento. Para tanto, fez-se pertinente compreender os estudos do pesquisador Vicente Jouve (2002), que aborda as dimensões da leitura enquanto estética, bem como as contribuições de Alberto Manguel (1997) que nos fazem compreender que a leitura é tão essencial na nossa vida como qualquer outra necessidade fisiológica. Por fim, e não menos importante, Michèle Petit (2009) contribui para nossos apontamentos quando apresenta a leitura como forma de autoconhecimento, libertação e discorre sobre a importância da mediação nesse processo. 


\section{LEITURA: ATITUDE DE AUTOCONHECIMENTO E LIBERTAÇÃO}

Não há dúvida de que a leitura é fator chave para a mudança social, nos diversos sentidos que a palavra mudança possa ter. Entretanto, esta prática desacompanhada de uma compreensão e interpretação significativa pode levar o sujeito à ilusão de que o fato de saber decifrar a junção das palavras é o suficiente para entender o mundo e agir nele. Ler é um processo de autoconhecimento, compreensão de mundo e de interação entre os sujeitos. Envolve atividades bem mais complexas que o simples fato decodificar os signos linguísticos. Nesse sentido, a leitura pode ser pensada como sinônimo de libertação e, sobre isso, o pesquisador Vicente Jouve (2002) esclarece-nos que "a leitura como experiência estética, é, portanto, sempre tanto libertação de alguma coisa quanto libertação para alguma coisa" (p. 108).

$\mathrm{O}$ autor explica que, antes do encadeamento libertador, ocorre um fenômeno que serve como gatilho para a chegada até a libertação de alguma coisa ou para alguma coisa, denominado de fruição estética, ou seja, o primeiro sentimento que aflora do leitor para com o texto. Esse primeiro processo suscitado no leitor, está relacionado com o seu imaginário, pois, no momento que o leitor imagina, ao mesmo, tempo recria e esse ciclo pode levá-lo ao que o autor chama de libertação.

Dessa forma, podemos ver a leitura como possibilidade de nos desenlaçar de algo que, antes da experiência com os textos, não nos sentíamos suficientemente confortáveis para soltar. Mesmo tendo consciência de que manter o enlace com o que nos aprisiona seja motivo de desconforto, a falta de segurança suscitada pela dificuldade em imaginar novos sentidos nos mantêm presos a velhas concepções que não nos servem mais. A partir da imaginação propiciada pela leitura, abre-se um leque de possibilidades para a construção de algo novo e transformador o que garante ao leitor uma sensação de liberdade.

Nesse sentido, faz-se pertinente apresentarmos o conceito de leitura de Jouve (2002), quando ele declara que essa prática perpassa por cinco dimensões. Em primeiro lugar o autor menciona a neurofisiológica, pois, segundo ele, sem as funções cerebrais a leitura não seria possível, uma vez que, necessitamos do processo visual e das demais funções do cérebro para que ela, a partir da decifração e memorização dos signos, aconteça.

Em seguida, nos explica a dimensão cognitiva que se baseia no pressuposto de que 
o leitor deve obter um saber mínimo para dar continuidade a leitura e, ao mesmo tempo, exige-se um esforço para a abstração. Sobre a dimensão da afetividade, Jouve retoma a importância das emoções, pois, a leitura promove a reflexão ligando o leitor às emoções que aquilo que lê o permite sentir. Na dimensão argumentativa, por sua vez, o autor prepara no texto um discurso de engajamento dele com o mundo e com os demais seres. E, por fim, o processo simbólico se dá na medida em que acontece a interação do leitor com o texto e a ressignificação desse texto relacionando com suas vivências.

Como se pode observar, a importância da leitura vai muito além do que dizem conhecidos e disseminados conceitos sobre ela, que a tratam apenas como instrumento decodificador dos signos linguísticos, utilizada para se ter acesso ao saber, de forma útil e prática. Como por exemplo, a realização da leitura de um manual de instruções de um eletrodoméstico. Não se pode negar que essa também é uma das atribuições importantes da leitura, entretanto, se restringe a uma leitura de sobrevivência, ou seja, aquela realizada para conseguir êxito nas questões cotidianas, tais como, para o exercício da profissão, vida escolar ou curiosidades pessoais. Contudo, é por meio da leitura que podemos agregar a palavra, o mundo e a nós mesmos outros diversos significados indispensáveis. Nesse sentido, Petit (2009) acrescenta:

Ler permite ao leitor, às vezes, decifrar sua própria experiência. É o texto que lê o leitor, de certo modo é ele que o revela; é o texto que sabe muito sobre o leitor, de regiões dele que ele mesmo não saberia nomear. As palavras do texto constituem o leitor, lhe dão um lugar (PETIT, 2009, p.38).

Ao considerarmos as palavras da autora podemos evidenciar a amplitude que tem o ato de ler, visto que pode auxiliar o leitor a entender, primeiramente, sua existência, passando por um processo de compreensão acerca do lugar que ocupa no mundo e, a partir disso, escolher para onde pretende caminhar ou onde pretende se fixar no que diz respeito às suas concepções.

Esses conhecimentos podem chegar ao leitor de várias formas no âmbito do pensamento. Por exemplo: o que quero mudar ou manter nas minhas concepções, a partir das reflexões promovidas após uma leitura, diz respeito a buscar um novo caminho, construir uma nova história profissional ou pessoal motivados por uma leitura que tenha 
mostrado o lugar onde se está e que tenha influenciado a descoberta de um novo espaço no mundo a ser conquistado.

Petit (2009) também reconhece que "a leitura é um meio para se ter acesso ao saber, aos conhecimentos formais e, sendo assim, pode modificar as linhas de nosso destino escolar, profissional e social" (p. 61). Portanto, se justifica a importância de fomentar a leitura e possibilitar que o ato de ler seja percebido como indispensável na vida das pessoas em todas as fases de suas vidas. Dessa forma, deixa de ser vista apenas como uma tarefa que se limita ao processo de escolarização e que, muitas vezes, acaba perdendo o sentido após esse período.

A partir do momento em que o leitor passa a ver a leitura como forma de conhecerse a si e ao mundo, perceberá que o ato de ler é necessário durante toda sua vida. Verá sua existência como um processo mutável e que, a cada mudança, há um novo enigma; e, por sua vez, perceberá que decifrar enigmas tem relação com as múltiplas possibilidades que a leitura abre ao leitor.

Sem a informação que adquirimos, também, por intermédio do que lemos, alguns acessos nos são negados e difíceis de serem compreendidos. Por vezes, podem ser traumáticos, simplesmente pela falta de conhecimentos básicos, o que poderia ser resolvido por meio da leitura. Muitas vezes, nossas dúvidas são tão íntimas que a melhor opção é conversar com alguém que nos dê as respostas sem balbuciar palavras, mas que, de forma sutil, deposite em nossa mente inúmeras alternativas de reflexão que possibilitem o esclarecimento das nossas incertezas.

E quem seria esse alguém? Podemos dizer que esse diálogo que favorece a resolução dos nossos enigmas pode ser alcançado a partir da leitura. Com ela, alcançamos a interpretação dos códigos escritos e chegamos às reflexões que, por fim, nos fazem compreender. Afinal, como nos explica Alberto Manguel (1997) quando afirma que "lemos para compreender, ou para começar a compreender. Não podemos deixar de ler. Ler, quase como respirar, é nossa função essencial" (p. 20).

Se pensarmos na leitura como forma de compreender o mundo e não só como decodificação de palavras escritas, damos a ela significados encantadores. Dessa maneira, percebemos que, na verdade, começamos a ler desde o momento do nosso nascimento, e não quando somos alfabetizados. Por exemplo, logo após sair do ventre da mãe, a criança 
inicia sua trajetória leitora. Ao reconhecer o novo ambiente, ao olhar para a face da mãe enquanto ela o amamenta, são também formas de leitura e compreensão do mundo. Nas palavras de Manguel,

Ler as letras de uma página é apenas um de seus muitos disfarces. $\mathrm{O}$ astrônomo lendo um mapa de estrelas que não existem mais; o arquiteto japonês lendo a terra sobre a qual será erguida uma casa, de modo a protegê-la das forças malignas; o zoólogo lendo os rastros de animais na floresta; o jogador lendo os gestos do parceiro antes de jogar a carta vencedora; a dançarina lendo as notações do coreógrafo e o público lendo os movimentos da dançarina no palco; o tecelão lendo o desenho intrincado de um tapete sendo tecido; o organista lendo várias linhas musicais simultâneas orquestradas na página; os pais lendo nos rosto do bebê sinais de alegria, medo ou admiração; o adivinho chinês lendo as marcas antigas na carapaça de uma tartaruga; o amante lendo cegamente o corpo amado à noite, sob os lençóis; o psiquiatra ajudando os pacientes a ler seus sonhos perturbadores; o pescador havaiano lendo as correntes do oceano ao mergulhar a mão na água; o agricultor lendo o tempo no céu - Todos compartilham com os leitores de livros a arte de decifrar e traduzir signos (MANGUEL, 1997, p. 19).

Vemos, então, que lemos tudo a nossa volta e, dessa leitura, depreendemos e construímos nossos saberes e definimos quem somos. Podemos, ainda, acrescentar à leitura o seu poder terapêutico. É possível que, à primeira vista, cause estranheza tentar relacionar leitura e terapia, mas, por que não pensar que nos momentos difíceis ou traumáticos a leitura, com o seu poder mágico, pode oferecer momentos de cura ou alívio para as nossas dores?

No momento que ela é capaz de nos transportar para um lugar seguro, tranquilo, e ainda nos possibilita dialogar com os personagens do texto, diminuindo nossa solidão, as dores que nos atribulam podem diminuir ou se desfazer. Dessa forma, se Manguel (1997) nos ensina que deciframos signos que nos ajudam a viver, a leitura pode sim, nos deslocar até nossos interiores a fim de que possamos nos reconstruir de forma positiva.

Independente do olhar ou do conceito que se utiliza para entender o que é a leitura, é possível enxergá-la de diversas formas, mas, dificilmente, irá encontrar alguma opção que lhe aponte o ato de ler como algo inútil ou apenas servindo como instrumento decodificador utilizado para solucionar os obstáculos diários. Ela vai além disso. Ela pode sim, tanto tirar como colocar "pedras em nosso caminho", pois da mesma forma que pode acalmar o coração, pode também, aflorar emoções, desestabilizar e abalar alicerces há 
muito firmados. Isso porque, ao ir além da decodificação, o ato de ler abre caminhos e estes caminhos são incertos. Se o leitor aceitar o convite para trilhar este percurso, talvez nem ele saberá onde ele vai chegar.

Nesse sentido, é importante destacar que a pesquisa-ação que realizamos procurou revelar as vertentes da leitura que permitem a interação do leitor com o texto, por acreditar que nessa interação possa haver construções, desconstruções e transformações de ideias e de pessoas. Trata-se de ver a leitura como uma possibilidade de construção da identidade do leitor, como menciona Petit (2009) quando diz que a leitura pode ser, em todas as idades, justamente um caminho privilegiado para se construir, se pensar, dar um sentido a própria experiência, a própria vida; para dar voz a seu sofrimento, dar forma a seus desejos e sonhos.

Ao defender a ideia do autoconhecimento propiciado pela leitura, a autora afirma que o leitor passa a entender o mundo que o cerca e, a partir disso, conseguirá agir nele conforme suas convicções e não pelo que lhe é imposto e este é o caminho para tornar-se cidadão ativo. Conforme menciona Petit (2009), por meio da difusão da leitura cria-se certo número de condições propícias para o exercício ativo da cidadania.

Observamos que a leitura pode servir para inúmeros fins, mas quando a palavra for usada em sentido profundo e fizer com que possamos olhar para dentro de nós mesmos, podemos tê-la como um remédio eficaz contra a manipulação e como uma mão invisível que se entrelaçará às nossas mãos e nos fará andar. Não temos como saber se andaremos pelo melhor caminho, mas podemos ter a certeza que por onde andarmos seremos guiados pelas interpretações realizadas a partir das nossas lentes e não das de outros. Deste modo, a única coisa, mas não pouca, que nos é garantida é a nossa autonomia no que diz respeito a nossos pensamentos. Portanto, a fidelidade ao que acreditamos estará protegida e, somente dessa maneira, é possível que sejamos os verdadeiros donos dos nossos destinos.

\section{O PROCESSO DE EXTRAÇÃO E LAPIDAÇÃO DA JOIA - LEITOR}

Os dados que trazemos neste trabalho tratam do imponderável, por isso, não há como trazer resultados numéricos, isso porque trata-se de uma pesquisa descritiva que se baseou em observações e análises de diversos aspectos subjetivos dos estudantes. Essa abordagem qualitativa, de acordo com Minayo, 
Responde a questões muito particulares. Ela se preocupa, nas ciências sociais, com um nível de realidade que não pode ser quantificado. Ou seja, ela trabalha com o universo de significados, motivos, aspirações, crenças, valores e atitudes, o que corresponde a um espaço mais profundo das relações, dos processos e dos fenômenos que não podem ser reduzidos à operacionalização de variáveis (MINAYO, 2001, p. 21).

Por meio dessa abordagem é possível identificar e analisar de forma aprofundada os dados que não podem ser mensurados. Nesse sentido, podemos citar como dados não quantificáveis a observação e análise comportamental, as percepções, as intenções e os sentimentos. Em encontros que perpassaram, aproximadamente, quatro meses, realizamos a pesquisa-ação com os estudantes que tiveram, do início ao fim, participação ativa, tanto na escolha dos temas/leituras que líamos e discutíamos em nossos encontros, quanto na produção de material que gerou uma ação concreta de mediação leitora na própria escola.

A coleta de dados se deu a partir de observações durante as aulas de língua portuguesa e de perguntas abertas sobre quais assuntos são interessantes para cada estudante dessa turma. A opção por perguntar sobre os assuntos interessantes ao invés de questionar "o que você gosta de ler" deu-se por pensar que talvez o público-alvo não tinha a leitura como prática habitual, o que se pôde comprovar no decorrer dos encontros. A intenção dessa proposta foi de apresentar aos estudantes uma leitura que possa ser significativa para eles/elas. Por isso, é preciso estar atento às necessidades e interesses do leitor e ouvi-los antes de sugerir uma nova leitura, pois

[o] que faz a felicidade de um entediará ou angustiará ao outro, tamanha é a diferença entre os leitores: de idade, sexo, geração, contextos sociais e culturais nos quais eles vivem, a história própria de cada um e a qual eles devem enfrentar. Tamanho é o inesperado que aí se encontra: pois os relatos, as frases que lhes falam que os revelam que os ajudam a dar sentido à sua vida e a resistir são frequentemente muito surpreendentes (PETIT, 2009, p. 174-175).

Após analisar os interesses que cada estudante demonstrou, foi possível elaborar um projeto de ensino que trabalhou textos de diversos gêneros e de temáticas sugeridas por eles/elas. Realizamos um total de sete encontros. No primeiro, antes de iniciar as leituras os estudantes responderam a seguinte questão que chamamos de "Pré-mediação": 
"Quem eu sou e como vejo o mundo?". Ao final de cada um dos sete encontros, que chamamos de "Mediação 1, 2, 3..." os estudantes responderam: "O que os textos de hoje disseram sobre mim e sobre o mundo?". No último encontro, os estudantes novamente responderam a primeira pergunta que chamamos de "Pós-mediações", "Quem sou eu e como vejo o mundo?".

Para manter a ética da pesquisa, utilizamos pseudônimos para cada estudante. Por acreditar que cada leitor, antes de sê-lo, é pedra bruta, que precisa ser lapidada, e também para representar o enorme carinho que temos por esses estudantes, nomeamos cada um/uma com o nome de uma pedra preciosa e, para isso, relacionamos a personalidade de cada um/uma com as características de uma pedra. São elas: Diamante, Rubi, Esmeralda, Jade, Safira, Turquesa e Ametista. Como podemos notar, algumas das pedras misturaramse aos pedregulhos do caminho e não pudemos recolocá-las aqui. Isso ocorreu porque, no decorrer do projeto, houve a transferência de um deles para outra escola e, outros dois, por não comparecerem em diversas aulas, participaram parcialmente da pesquisa e, por conta disso, não conseguiram responder a questões que julgamos ser essenciais para esta investigação. Neste caso, foram analisados os dados referentes à participação dos sete anteriormente citados dos quais, nos apoiaremos em alguns escritos, e reflexões.

\section{EXPLORANDO A MINA}

Ao trazermos para este trabalho alguns dos escritos das joias raras participantes da pesquisa-ação que realizamos, precisamos focar nosso olhar para o que Jorge Larrosa (2016) nos fala sobre a experiência de leitura nos (trans) formar; sobre o fato de ela possibilitar que algo aconteça em nós muito mais do que simplesmente aconteça diante de nós. Ou seja, não podemos ser os mesmos depois de uma leitura, pois ela nos forma, deforma e transforma.

Antes de apresentar a trajetória percorrida em cada encontro com os estudantes, faz-se necessário justificar que as temáticas trabalhadas durante o projeto foram sugeridas por eles. A escolha dos textos foi feita levando em conta os assuntos de seus interesses, bem como o nível de aprendizagem/maturidade que pudemos perceber na turma, quando acompanhamos as aulas de pré-estágio. Ainda destacamos que fizemos uso de diferentes tipologias textuais, tanto literárias quanto não literárias, que puderam abarcar os conteúdos 
que deveriam ser trabalhados naquele período e que foram sugeridos pela professora regente.

Ademais, vale ressaltar que, ao realizarmos a seleção dos matérias, nos atentamos para que não tivessem um propósito utilitário e, sim, que pudessem despertar/aguçar a percepção estética dos textos. Acreditamos que esta seria uma forma de possibilitar infinitas reflexões, sensações e, por fim, permitir que cada estudante pudesse experimentar de forma única o que Larrosa (2011) chama de experiência de leitura.

Dessa forma, compartilhamos aqui uma resposta para a questão mediadora de número 4, no dia em que discutimos o assunto Preconceito. "O que os textos de hoje disseram sobre mim e sobre o mundo?". A resposta da joia Esmeralda foi: “A aula de hoje me fez pensar que muitos preconceitos já foram vencidos, porque, em outros tempos, se eu falasse que era bissexual acredito que haveria muito mais rejeição do que existe hoje em dia. Ainda sofro muito preconceito por causa disso, a minha própria mãe já me magoou muito dizendo que eu não deveria ter nascido já que sou tão estranho. Mas como falei, muita coisa já foi vencida e isso me dá esperança de vencer muito mais obstáculos”. O que notamos, aqui, é que a leitura também pressupõe alguns riscos para o leitor, uma vez que cada um pode receber um mesmo texto de forma diferente. E, para além disso, não é possível saber qual dimensão esse texto pode atingir. No caso de Esmeralda, o texto a levou para um lugar desconfortável, pois lhe trouxe à margem sua maior tristeza. Todavia, apesar de dolorosa, tais reflexões podem ser benéficas se analisarmos sob a ótica da escritora Michèle Petit quando diz:

\footnotetext{
O leitor vai ao deserto, fica diante de si mesmo; as palavras podem jogálo para fora de si mesmo, desalojá-lo de suas certezas, de seus "pertencimentos". Perde algumas plumas, mas eram plumas que alguém havia colocado nele, que não tinham necessariamente relação com ele. E às vezes tem vontade de soltar as amarras, de mudar de lugar (PETIT, 2009, p. 147).
}

Deste modo, indo ao encontro do que diz a autora, ao responder à Mediação 4, Jade se manifesta: “Os textos de hoje foram muito importantes, porque descobri que algumas coisas que eu penso são preconceitos e eu achava que não era. Fazemos muitas coisas sem pensar e isso é um grande erro". Vemos, então, que, sabiamente, Jade declara que um dos maiores problemas da sociedade provém da falta de habilidade das pessoas em 
refletir criticamente sobre si e sobre o mundo. Desta maneira, a cada novo encontro e a cada resposta desses estudantes é notável um aumento gradativo do brilho dessas pedras preciosas que vamos (re)descobrindo. Um brilho proveniente da lapidação que cada texto propicia. O brilho que trará luz para a trajetória de cada um, pois uma vez que experimentaram as delícias de pensar o mundo com autonomia, e de abrir-se para as várias possibilidades de saborear a liberdade advinda do texto, acredito que jamais retrocederão.

Outro exemplo que consideramos oportuno trazer aqui é acerca das reflexões do encontro que tratou da temática da anorexia. Para responder ao questionamento final da Mediação 3 “O que os textos de hoje disseram sobre mim e sobre o mundo?”, Rubi escreveu que havia compreendido que "Hoje, após o texto lido e os vídeos assistidos, descobri que se eu me sinto bem com o meu corpo, não preciso ficar tentando emagrecer o tempo todo para agradar aos outros. Ninguém deve fazer isso!”. Já Turmalina contribui dizendo: "A aula de hoje me ensinou que devo ter uma alimentação boa e aceitar meu corpo como ele é". Notamos que os relatos de Rubi e Turmalina mostram que a leitura abre também um acesso para o nosso interior e pode nos fazer explorar esse território de modo que possamos dar nome às dores e aos amores que sentimos. Isso corrobora o que vemos nos escritos de Petit: "Os textos lidos abrem aqui um caminho em direção à interioridade, aos territórios inexplorados da afetividade, das emoções, da sensibilidade; a tristeza ou a dor começam a ser denominadas" (2019, p. 108).

No encontro em que discutimos acerca do machismo, lemos algumas letras de canções que abordam a temática. São elas: "Amélia”, de Mário Lago e "Mulheres", de Martinho da Vila, "Desconstruindo Amélia", de Pitty e "Mulheres", de Doralycia e Silva. A proposta era que, na medida em que encontrassem situações de machismo, os estudantes deveriam relatar e discutir cada frase com a turma. Percebemos que se mantiveram engajados com as discussões e trouxeram relatos sobre situações de machismo que acontecem em suas casas.

Durante as discussões, evidenciamos a importância de estarmos informados sobre o assunto a fim de refletir sobre a sociedade, nossas relações interpessoais e, principalmente, sobre quais concepções machistas estão internalizadas em nós pois, identificá-las é o primeiro passo para tentar desconstruir e construir uma sociedade melhor. 
Nesse momento, Jade se posicionou da seguinte maneira: “Com algumas coisas que você está falando eu concordo, mas com outras não, porque vejo mulheres andando em vias movimentadas e com shorts extremamente curtos. Não acho isso certo, porque isso pode provocar os homens e por isso elas são agredidas". As considerações de Jade foram muito pertinentes, pois, nesse momento, ficou ainda mais clara a importância do trabalho que estávamos fazendo. Dizemos isso porque, mais do que imaginávamos, o machismo assombra as concepções das famílias desses estudantes e, consequentemente, se instala como verdade no pensamento desses jovens, como observado na fala de Jade, no momento em que diz que as mulheres estariam erradas em usar shorts curtos porque seria uma maneira de provocar os homens.

O mesmo tipo de pensamento, podemos verificar no relato de Turquesa que diz, o seguinte: "Meu pai é muito machista, vive maltratando e humilhando a minha mãe e eu. Nós duas somos a empregada dele. Ele fica sentado no sofá e temos que fazer tudo para ele, mas o que eu mais odeio é que meu irmão pode fazer o que quiser só por ser homem e eu não posso fazer quase nada porque sou mulher. Odeio meu pai”.

Para este encontro, apresentamos aos alunos a obra Sejamos todos Feministas, de Chimamanda Ngozi Adichie (2015), da qual lemos alguns trechos que mostram as dificuldades que as mulheres encontram na sociedade, simplesmente pelo fato de serem mulheres. O texto da autora aponta as discriminações sofridas por elas ao realizarem atividades consideradas masculinas e, no entanto, menosprezadas por isso. Após a leitura, alguns dos estudantes contribuíram com relatos de suas vidas que se relacionavam com os textos lidos em sala de aula.

Sendo assim, podemos perceber que, devido ao fato de que estes jovens estão diariamente expostos a diversas manifestações de machismo, alguns conceitos, como o que Jade mencionou, se tornam naturais e legitimados por eles. Por acreditar na possibilidade de construção de uma sociedade menos machista, estimulada pelo conceito de que "Ler é condição de estar no mundo, criando-o outra vez" (YUNES, 2002, p. 39), oferecemos aos estudantes a leitura como instrumento capaz de promover a reconstrução de um mundo onde as diferenças entre homens e mulheres sejam apenas as biológicas. 


\section{REVISTA $\mathbf{X}$}

\section{EXTRAÇÃO DA PEDRARIA: VALORAÇÃO DO BRILHO}

O instrumento, do qual nos apropriamos para proceder com as lapidações, se chama leitura. Foi com ela que instigamos o autoconhecimento, a curiosidade para entender o mundo e realizar a reflexão de forma crítica. Para que se possa avaliar se as hipóteses iniciais deste trabalho se cumpriram é importante explicar que, no primeiro encontro, antes das atividades, os sujeitos de pesquisa responderam à pergunta de Prémediação: “Como eu sou e como eu vejo o mundo?”. No último encontro, retomamos o questionamento inicial com o intuito de observar se algo mudou acerca do olhar sobre si mesmo e da maneira que esse leitor vê o mundo a partir dos textos. Como a pergunta foi a mesma, para melhor identificarmos as respostas, chamaremos de Pós-mediação para melhor analisarmos os resultados da pesquisa. Vale ressaltar, que no espaço entre a pergunta de pré e pós-mediação, a cada encontro, os estudantes foram expostos a diversas leituras e atividades que tinham como objetivo fazê-los refletir. Posto isso, apresentamos o Quadro 1, no qual contam as respostas dadas pelos estudantes no momento anterior e posterior à pesquisa- ação.

Quadro 1: Questionamentos pré-mediação e pós-mediação

\begin{tabular}{|c|c|c|}
\hline & QUESTIONAMENTO INICIAL & QUESTIONAMENTO FINAL \\
\hline & $\begin{array}{l}\text { Quem eu sou e como eu vejo o } \\
\text { mundo? }\end{array}$ & $\begin{array}{l}\text { Quem eu sou e como eu vejo o } \\
\text { mundo? }\end{array}$ \\
\hline Diamante & $\begin{array}{l}\text { "Eu me considero bastante ignorante e } \\
\text { vejo o mundo com bastante } \\
\text { preconceito" }\end{array}$ & $\begin{array}{l}\text { "Durante o projeto refleti sobre } \\
\text { muitos assuntos que eu ainda não } \\
\text { conhecia. Agora não faço certas } \\
\text { coisas que eu fazia e sei muito mais } \\
\text { sobre assuntos da vida." }\end{array}$ \\
\hline Ametista & $\begin{array}{l}\text { "Não sou perfeita, mas quem é } \\
\text { perfeito? O mundo é dos egoístas, só } \\
\text { os egoístas se dão bem." }\end{array}$ & $\begin{array}{l}\text { "Percebi que aulas com assuntos } \\
\text { envolventes e do cotidiano, ensinam } \\
\text { coisas que realmente vou levar para } \\
\text { a vida. Também foi bom perceber } \\
\text { que as coisas que eu sinto outras } \\
\text { pessoas também sentem. Assim } \\
\text { ficou mais fácil me entender e } \\
\text { entender um pouco mais sobre o } \\
\text { mundo." }\end{array}$ \\
\hline
\end{tabular}




\begin{tabular}{|c|c|c|}
\hline Esmeralda & $\begin{array}{l}\text { "Eu sinto que sou diferente de } \\
\text { algumas pessoas, pelo meu jeito e } \\
\text { pelas minhas características, pois, sou } \\
\text { um garoto de } 14 \text { anos, bissexual e } \\
\text { sofro bullying, mas sigo em frente e } \\
\text { sempre falo que é com as pedras que } \\
\text { eu construo o meu castelo. Eu vejo um } \\
\text { mundo muito preconceituoso e } \\
\text { machistas onde muitas coisas podem } \\
\text { mudar para melhor." }\end{array}$ & $\begin{array}{l}\text { "Eu continuo o mesmo de antes, } \\
\text { mas agora me sinto mais livre. } \\
\text { Ainda vejo um mundo cheio de } \\
\text { preconceito, mas acredito que com } \\
\text { respeito a gente pode mudar isso." }\end{array}$ \\
\hline Turquesa & $\begin{array}{l}\text { "Sou uma pessoa reservada, não gosto } \\
\text { de falar as coisas que penso e prefiro } \\
\text { ficar no meu canto. Sou uma pessoa } \\
\text { tímida e tenho gostos diferentes dos } \\
\text { meus amigos. Vejo o mundo como um } \\
\text { lugar que tem muito a ser descoberto, } \\
\text { a melhorar e mudar." }\end{array}$ & $\begin{array}{l}\text { "Na primeira vez que respondi essa } \\
\text { pergunta não me importei muito em } \\
\text { responder, mas após ter conhecido } \\
\text { muito sobre diversos assuntos, hoje } \\
\text { tenho pensamentos diferentes sobre } \\
\text { alguns assuntos." }\end{array}$ \\
\hline Jade & $\begin{array}{l}\text { "Eu tenho } 15 \text { anos, gosto de ouvir } \\
\text { música e tenho um sonho de morar } \\
\text { fora do Brasil". Vejo o mundo muito } \\
\text { injusto e ruim." }\end{array}$ & $\begin{array}{l}\text { "Agora vejo o mundo com outro } \\
\text { olhar, antes eu tinha alguns } \\
\text { preconceitos bobos e hoje percebo } \\
\text { que não tinha porque pensar daquela } \\
\text { forma. Antes eu apenas me } \\
\text { convencia e agia como os outros } \\
\text { falavam, hoje acho fundamental } \\
\text { pensar sobre as coisas." }\end{array}$ \\
\hline Safira & $\begin{array}{l}\text { "Eu gosto de ficar sozinha no meu } \\
\text { quarto. Meu sonho é ter uma casa com } \\
\text { as coisas que eu gosto. Eu vejo o } \\
\text { mundo como algo que tenho que } \\
\text { descobrir e me aventurar." }\end{array}$ & $\begin{array}{l}\text { "A cada aula meu pensamento } \\
\text { mudava. Cada texto lido mexia } \\
\text { comigo e me fazia pensar e isso foi } \\
\text { muito especial para mim." }\end{array}$ \\
\hline Rubi & $\begin{array}{l}\text { "Sou simpática, alegre e estudiosa. } \\
\text { Gosto de me divertir com meus } \\
\text { amigos e ajudar minha mãe em casa. } \\
\text { Eu gostaria que o mundo fosse } \\
\text { diferente, que todos vivessem em paz, } \\
\text { sem brigas e sem ódio." }\end{array}$ & $\begin{array}{l}\text { "As aulas e os textos foram } \\
\text { incríveis, abriram a minha mente, } \\
\text { me fizeram pensar sobre preconceito } \\
\text { e outras coisas muito importantes. } \\
\text { Agora consigo pensar sobre o } \\
\text { mundo sozinha sem precisar repetir } \\
\text { as opiniões das outras pessoas." }\end{array}$ \\
\hline
\end{tabular}

Fonte: elaborado pela autora (2019).

As reflexões que os textos nos suscitam nos lapidam ao ponto de conseguirmos olhar para nós mesmos e sabermos ler o que estamos vendo. Para além disso, mostra em 
que mundo o sujeito se encontra, quais os desafios desse lugar e o que precisa compreender para que esse mundo se torne um lugar que possa ser habitado com alegria, igualdade e paz. Essas descobertas que a leitura proporciona podem fazer com que o leitor sinta o sabor da liberdade e da autonomia, e esse é um caminho sem volta pois, ao vivenciá-las, não será mais possível aceitar passivamente o que lhe é imposto sem possibilidades de reflexão. Dessa maneira, pode-se entender por que a leitura em determinadas situações pode ser vista como atividade perigosa, pois pode comprometer a ordem estabelecida e os dogmas firmados.

\begin{abstract}
Não é sem motivo que os poderes tenham temido tanto as leituras não controladas: a apropriação da língua, o acesso ao conhecimento, como também a tomada de distância, a elaboração de um mundo próprio, de uma reflexão própria, propiciados pela leitura, podem ser o pré-requisito, a via de acesso ao exercício de um verdadeiro direito a cidadania (PETIT, 2009, p. 148).
\end{abstract}

Dessa forma, ao analisarmos os resultados mostrados no Quadro 1, percebemos o quão benéficas foram as mediações realizadas em cada encontro com os estudantes. Suas escritas revelam que, por intermédio da leitura, eles se permitiram compreender um pouco mais sobre si e sobre a sociedade que estão inseridos, visto que foi possível observar nos relatos de todos os participantes da pesquisa que nenhum deles/delas se manteve com as mesmas concepções sobre si e sobre o mundo que relataram no início da pesquisa-ação.

Primeiramente, esses dados mostram algo que consideramos de extrema importância, o fato de que todos os participantes mostraram ter realizado exercícios de reflexão a partir dos textos abordados. Tal informação pode ser evidenciada ao identificarmos que todos/ todas apresentaram respostas divergentes para a mesma pergunta simplesmente por esses questionamentos terem sido feitos em diferentes momentos durante a pesquisa-ação (uma anterior às mediações e a outra posterior às mediações). Se os leitores analisados nessa pesquisa não tivessem sido tocados de nenhuma forma pelas leituras e reflexões trazidas por elas, talvez não houvesse nenhuma disparidade entre a resposta inicial e a final. 


\section{CONSIDERAÇÕES FINAIS}

O presente trabalho fez uso da pesquisa-ação para mediar a leitura em turma de estudantes de oitavo ano de escola pública a fim de evidenciar suas relações com o ato de ler, ao mesmo tempo em que essa atividade pudesse despertar seus olhares para seus interiores. Tal investigação se fez pertinente porque tínhamos como objetivo a formação de leitores que colocassem em suas vidas a leitura como uma possibilidade de verem-se a si mesmos e o mundo por meio dos textos e, com isso, tornarem-se mais críticos e envolvidos com a leitura. Para tanto, foi necessário ir em busca de teorias que fossem capazes de nos mostrar o caminho que deveríamos percorrer, a fim de que pudéssemos embasar as práticas pedagógicas que seriam utilizadas ao longo do trabalho. Assim sendo, para que o trabalho fosse profícuo, foi necessário, além de identificar as ações que poderiam ser utilizadas pelo mediador a fim de contribuir para formação de leitores, a aplicação dessas ações que a pesquisa teórica apontou como benéficas para a formação de leitores.

Desse modo, os resultados provenientes da prática foram analisados e foi possível compreender que as teorias haviam nos direcionado para o caminho certo, uma vez que, a indicação dada pelos referenciais teóricos, chegamos ao que simbolicamente chamamos de tesouro: uma mina de pedras preciosas, na qual foi possível trabalhar na lapidação. À primeira vista, estas pedras se apresentaram brutas, mas, depois de polidas, transformaram-se em joias e o brilho iluminou os seus e, como não poderia ser diferente, o nosso mundo também. Assim, possibilitamos que, de pedregulhos comuns, extraíssemos pedras raras que descobriram seu potencial e seu valor a partir do momento em que ousaram sair da mina.

Alunos pouco leitores que passam a ler, além de textos, a si mesmos e também o mundo, ao mesmo tempo que se (re)descobrem, podem vir a tornar-se mediadores de leitura atuando em seu próprio meio. Eis a magia dos livros agindo e transformando pessoas e realidades! O que vimos nos primeiros encontros foi mais descrédito, infelicidade e desamor do que qualquer outra coisa. A falta da figura do mediador de leitura na primeira infância ficou evidente em muitas falas dos participantes. Além disso, o fato de não terem presente na memória alguém que os tenha contado histórias revela esta ausência. E esta falta deixou grandes lacunas em suas sensibilidades. 
É a partir disso, que vemos a necessidade de mediar a leitura na escola como uma atividade de extrema importância. Oportunizar o contato com diferentes textos, de distintos gêneros aos estudantes é fazê-los exploradores de suas próprias minas, é proporcionar o redirecionamento do olhar para dentro de si mesmos a fim de (trans) formar suas vidas, já que nem sempre a família pode cumprir com este papel. O que conseguimos realizar durante os encontros mostra que, com auxílio dos textos, é possível parar a conturbada vida, parar a tão engessada grade curricular para olharmos para dentro de nós mesmos. Foi preciso silenciar o exterior, e a nós mesmos, e deixar ouvir o texto agir em nós. Somente na pausa e no silêncio foi possível, segundo Larrosa (2003), que algo nos passasse, que algo acontecesse em nós. E aconteceu: de pedra bruta à joia rara nos transformamos.

\section{REFERÊNCIAS}

CHIMAMANDA, A. A. Sejamos todos feministas. 2015. Disponível em: $<$ http://professor.pucgoias.edu.br/SiteDocente/admin/arquivosUpload/7771/material/LIVR O\%20Sejamos-Todos-Feministas.pdf >. Acesso em: 20 mar. 2019.

JOUVE, V. A leitura. São Paulo: Editora Unesp, 2002.

LARROSA, J. Tremores: escritos sobre experiência. Tradução de Cristina Antunes e João Wanderley Geraldi. 1.ed. 2.reimp. Belo Horizonte: Autêntica Editora, 2016.

2011.

. Experiência e alteridade em educação. Reflexão e Ação, v. 19, n. 2, p. 04-27, La experiencia de la lectura. México: FCE, 2003.

MANGUEL, A. Uma história da leitura. São Paulo: Companhia das letras, 1997.

MINAYO, M. C. (Org.) Pesquisa Social: teoria, método e criatividade. Petrópolis: Vozes, 2001.

PETIT, M. Os jovens e a leitura: uma nova perspectiva. 2.ed. São Paulo: Editora 34, 2009.

YUNES, E. Pensar a leitura: complexidade. Rio de Janeiro: Ed. PUC-Rio; São Paulo: Loyola, 2002. 